\title{
Does a Cemented Cage Improve Revision THA for Severe Acetabular Defects?
}

\author{
Erik Hansen MD, David Shearer MD, MPH, \\ Michael D. Ries MD
}

Published online: 21 September 2010

(c) The Author(s) 2010. This article is published with open access at Springerlink.com

\begin{abstract}
Background Evidence suggests a growing incidence of revision total hip arthroplasty (THA) including a subset with large acetabular defects. Revision THA for severe acetabular bone loss is associated with a relatively high rate of mechanical failure.

Questions/purposes We questioned whether cementing a cage to the reconstructed acetabular defect and pelvis would improve the rate of mechanical failure for patients with Type 3 defects (Paprosky et al.) with and without pelvic discontinuity in comparison to historical controls.

Methods We retrospectively collected data on 33 patients who underwent 35 revision THAs using an acetabular reconstruction cage cemented to morselized allograft and either structural allograft or trabecular metal augmentation for Type 3 defects in the presence $(n=13)$ and absence $(\mathrm{n}=22)$ of pelvic discontinuity at a mean followup of 59 months (range, 24-92 months). The primary outcome was mechanical failure, defined as revision of the acetabular reconstruction for aseptic loosening.

Results Revision surgery for mechanical failure occurred in four of the 13 patients with pelvic discontinuity and two
\end{abstract}

One or more of the authors (MDR) is a consultant for Smith \& Nephew.

Each author certifies that his institution either has approved or waived approval for the human protocol for this investigation and that all investigations were conducted in conformity with ethical principles of research.

This work was performed at the University of California, San Francisco Medical Center, San Francisco, CA, USA.

E. Hansen, D. Shearer, M. D. Ries ( $\varangle)$

Department of Orthopaedic Surgery, University of California,

San Francisco, 500 Parnassus Avenue, MU 320-W,

San Francisco, CA 94143, USA

e-mail: riesm@orthosurg.ucsf.edu of the 22 patients without discontinuity. Radiographic loosening occurred in one patient with and one patient without pelvic discontinuity. Seven of the 35 revisions were subsequently revised for deep infection all in patients who were immunocompromised.

Conclusions Cementing the cage to the pelvis can offer an advantage for treating severe acetabular defects. Trabecular metal augmentation appears to provide better initial mechanical stability than a structural allograft, but successful allograft reconstruction may restore bone stock. Level of Evidence Level IV, therapeutic study. See Guidelines for Authors for a complete description of levels of evidence.

\section{Introduction}

Over the past decade, the ratio of revision to primary hip arthroplasty has remained relatively constant at $17 \%$, which is two times that of knee arthroplasty [20]. Because the indications for total joint arthroplasty are expanding to include younger patients with higher expected activity and demands, the number of revision THAs performed in the United States is projected to double by the year 2026 [21]. Aseptic loosening of the femoral and acetabular components remains one of the major indications for revision hip arthroplasty, representing $20 \%$ to $75 \%$ of all cases [2, 5, 23].

Reconstruction of the acetabulum in the setting of severe bone loss is one of the most challenging problems in revision hip arthroplasty. In studies of all acetabular revisions, including those without major bone loss, reported rates of aseptic loosening range from $1.8 \%$ to $3 \%$ at 10 years using a cementless acetabular cup with screw fixation [22, 35]. In contrast, in cases of massive acetabular bone loss, defined as less than $50 \%$ host bone support, rates 
of aseptic loosening range from $12.5 \%$ to $34 \%$ over an equivalent or shorter period of followup [3, 11, 17, 29, 31], indicating better methods of reconstruction are needed for this population.

Paprosky et al. [26] developed a classification system for describing acetabular bone loss based on an assessment of radiographic parameters and intraoperative findings. Type 3 defects are the most severe and indicate major destruction of the acetabular rim and supporting structures resulting in more than $2 \mathrm{~cm}$ of component migration [26]. Type $3 \mathrm{~A}$ and $3 \mathrm{~B}$ defects differ in regard to the degree of involvement of the superior rim of the acetabulum, the teardrop, and the ischium. Pelvic discontinuity, the most severe type of acetabular defect, is defined by separation of the superior pelvis from the ischium inferiorly. The degree of bone loss in these clinical situations compromises initial acetabular implant support and diminishes the success of potential treatment options.

Current strategies for these severe acetabular defects rely on structural allograft $[11,12,26,32]$ and reconstruction cages $[3,4,30]$ or trabecular metal augmentation with a cementless hemispheric cup [34, 37]. Cage reconstruction provides good initial stability, but the inability for biologic fixation at the cage-bone interface can compromise long-term success $[1,13,27]$. In an effort to improve both the initial and long-term fixation of cage reconstructions for Type 3 acetabular defects and cases of pelvic discontinuity, since August 2001 we have used a technique in which a grit-blasted titanium cage is cemented to morselized and/or structural allograft and the pelvis.

The purposes of our investigation were to (1) describe a novel technique of cage cementation for patients with severe acetabular defects; (2) compare the survivorship of the technique to historical controls using mechanical failure as a primary end point in patients with Type 3 defects with and without pelvic discontinuity; and (3) analyze patients who required further revision to determine the ability of this technique to restore adequate bone stock and facilitate conversion to a cementless hemispheric cup.

\section{Patients and Methods}

We retrospectively collected data on all 58 patients (60 hips) who underwent revision hip arthroplasty with a gritblasted titanium cage cemented to morselized and/or structural allograft and the pelvis at UCSF Medical Center between 2001 and 2008. Indications for cemented cage reconstruction in revision THA included segmental bone loss of the acetabular rim, which precluded stable fixation of a cementless hemispheric component without structural augmentation of the rim, or a relatively intact acetabular rim in association with severe osteopenia, which precluded stable fixation of a cementless hemispheric cup with screws. Eleven patients (11 hips) had acetabular bone loss consistent with Type 2C defects and were excluded from the analysis. An additional six patients (six hips) who died before the 2-year followup were also excluded. At the time of their deaths, they all had well-functioning acetabular reconstructions. Despite multiple attempts at contact, seven additional patients were lost to followup less than 2 years after surgery (range, date of discharge to 6 months). The remaining 34 patients (36 hips) with at least 2 years of clinical and radiographic followup (mean, 59 months; range, 24-92 months) were included in the analysis. No patients were recalled specifically for this study; all data were obtained from charts and radiographs. This study was approved by the University of California, San Francisco Institutional Review Board through expedited review.

The cohort included seven men $(21 \%)$ and 27 women (79\%) with an average age at the time of revision surgery of 63.3 years (range, 44-86 years). Diagnosis at the time of index arthroplasty was osteoarthritis in 12 patients, avascular necrosis in eight patients, posttraumatic arthritis in eight patients, rheumatoid arthritis in three patients, and developmental dysplasia of the hip in three patients (Table 1). The average number of procedures performed before the present acetabular revision was 3.1 (range, 1-20). Diagnosis at the time of cemented cage reconstruction was as follows: aseptic loosening/mechanical failure $(n=28)$, instability $(n=1)$, reimplant for infection $(n=4)$, and periprosthetic fracture $(n=1)$.

Clinical data were prospectively entered into an arthroplasty database, which was later reviewed to conduct this study. We used preoperative radiographs and intraoperative findings as documented by the operative record to classify the acetabular defects according to the classification nomenclature of the American Academy of Orthopaedic Surgeons (AAOS) Committee on the hip, Paprosky et al. [22], and Gross et al. [6, 26]. Using the AAOS classification, the acetabular defects were as follows: Type $1(\mathrm{n}=14)$, Type $2(\mathrm{n}=0)$, Type $3(\mathrm{n}=8)$, and Type $4(n=13)$. Based on the classification of Paprosky et al., there were 14 Type $3 \mathrm{~A}$, eight Type 3B, and 13 cases of pelvic discontinuity. According to the classification of Gross et al., the following acetabular defects were seen: Type IV $(\mathrm{n}=22)$ and Type V $(\mathrm{n}=13)$ (Table 1$)$.

Beginning in April 2004, trabecular metal augments (Zimmer, Warsaw, IN) became available and were used as an alternative to structural allograft in patients with failed allografts or in elderly patients in whom restoration or bone stock for possible future rerevision THA was not considered an important goal of surgery. Trabecular metal augments were used in the same manner as structural allograft with a cemented cage for Type 3 acetabular defects. Ten patients (10 hips) with trabecular metal 
Table 1. Pre- and postoperative demographic information

\begin{tabular}{|c|c|c|c|}
\hline \multirow[t]{2}{*}{ Variable } & \multicolumn{2}{|l|}{ Allograft } & \multirow{2}{*}{$\begin{array}{l}\text { Trabecular } \\
\text { metal } \\
(\mathrm{n}=10)\end{array}$} \\
\hline & $\begin{array}{l}\text { No PD } \\
(\mathrm{n}=22)\end{array}$ & $\begin{array}{l}\text { PD } \\
(\mathrm{n}=14)\end{array}$ & \\
\hline Age, mean years (SD) & $62.8(13.7)$ & $64.3(8.9)$ & $60.3(15.5)$ \\
\hline Female, number (\%) & $17(77)$ & $10(71)$ & $8(80)$ \\
\hline \multicolumn{4}{|l|}{ Initial indication, number $(\%)$} \\
\hline Primary OA & $7(32)$ & $6(43)$ & $1(14)$ \\
\hline Inflammatory & $2(9)$ & $1(7)$ & $2(29)$ \\
\hline DDH & $5(23)$ & $0(0)$ & $1(14)$ \\
\hline Posttraumatic & $6(27)$ & $1(7)$ & $1(14)$ \\
\hline AVN & $2(9)$ & $6(43)$ & $1(14)$ \\
\hline Other/not reported & $0(0)$ & $0(0)$ & $1(14)$ \\
\hline \multicolumn{4}{|l|}{ Current indication, number $(\%)$} \\
\hline Mechanical failure & $18(82)$ & $9(64)$ & $7(70)$ \\
\hline Instability & $2(9.1)$ & $3(21)$ & 0 \\
\hline Reimplant & $1(4.5)$ & $2(14)$ & $2(20)$ \\
\hline Periprosthetic fracture & $1(4.5)$ & $0(0)$ & $1(10)$ \\
\hline $\begin{array}{l}\text { Prior surgeries, number } \\
\quad \text { (range) }\end{array}$ & $3.4(1-20)$ & $2.7(1-7)$ & $3.9(1-6)$ \\
\hline Cup size, mean (SD) & $57.6(3.3)$ & $59(3.1)$ & N/A \\
\hline Head size, mean, (SD) & $29.9(3.1)$ & $30(4)$ & N/A \\
\hline $\begin{array}{l}\text { Estimated blood loss, } \\
\text { mean }(\mathrm{SD})\end{array}$ & $1219(941)$ & 945 (337) & $1450(526)$ \\
\hline Operative time, mean (SD) & $173(46)$ & $175(35)$ & N/A \\
\hline $\begin{array}{l}\text { Length of hospital stay, } \\
\text { mean (SD) }\end{array}$ & $7(4)$ & $8(6)$ & $7(5)$ \\
\hline
\end{tabular}

$\mathrm{PD}=$ pelvic discontinuity; $\mathrm{OA}=$ osteoarthritis; $\mathrm{DDH}=$ developmental dysplasia of the hip; AVN = avascular necrosis; $\mathrm{N} / \mathrm{A}=$ not available.

augmentation were followed up for a minimum of 10 months (mean, 38 months; range, 10-69 months) (Table 1). Four patients in this group of 10 had been previously treated using cemented cage reconstruction that failed and were revised with trabecular metal augments. These four patients are thus considered part of the cage reconstruction group up until failure and thereafter considered part of the trabecular metal group. Pelvic discontinuity was present in four and absent in six of the patients treated with trabecular metal.

All surgery was performed by the senior author (MDR). We used a posterior approach with extended trochanteric osteotomy, if necessary, for removal of the femoral component and cement. The acetabular component was removed using extraction devices, preserving as much bone stock as possible. Cystic areas were aggressively débrided. We then inspected the acetabulum to identify areas of osteolysis, determine the type of bony defects remaining, and assess for the presence of pelvic discontinuity. The acetabular bone bed was reamed with hemispheric reamers to the intact rim. A trial shell was placed and manually
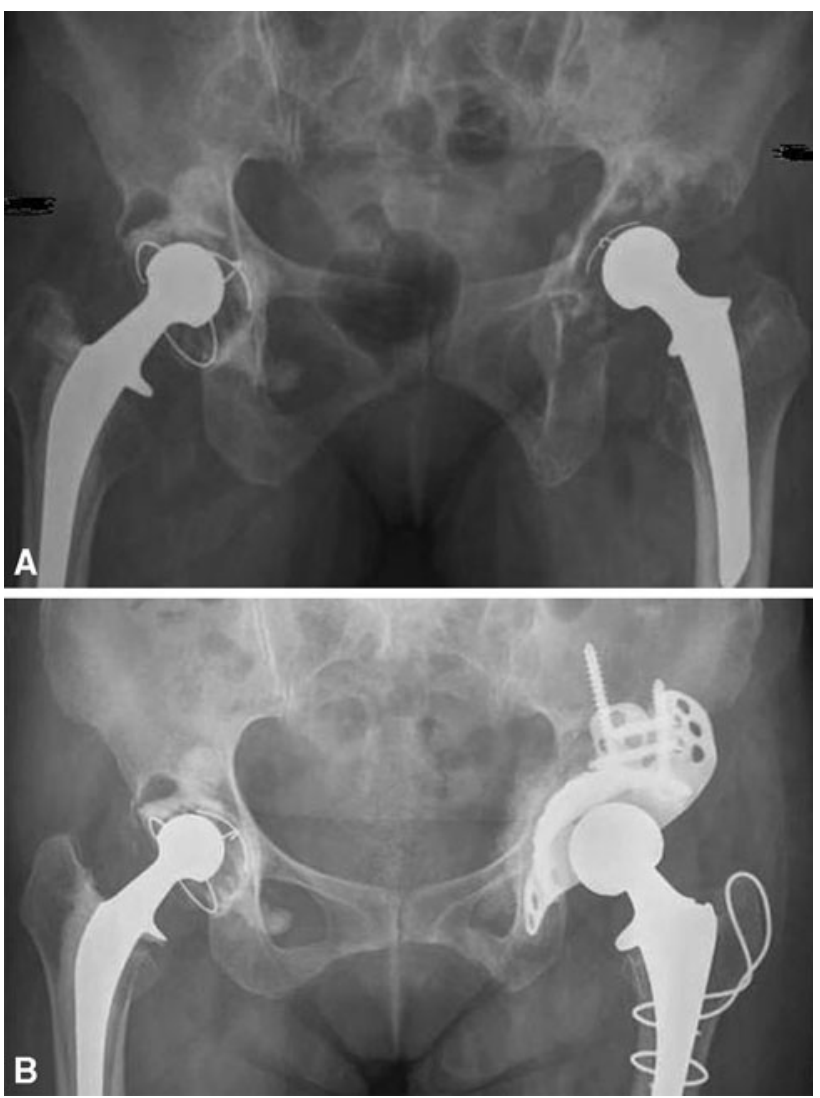

Fig. 1A-B (A) A preoperative AP pelvic radiograph demonstrates acetabular osteolysis of the left hip resulting in a Type 3A segmental defect. (B) A postoperative radiograph demonstrates cemented cage reconstruction with superior structural and medial morsellized allograft.

distracted posterosuperiorly. If displacement of the shell did not occur, the acetabulum was reconstructed with a hemispheric porous-coated cup, morselized allograft, and screw fixation of the shell. If instability of the trial shell was observed, then superior and posterior segmental defects that precluded stable fixation of a cementless hemispheric cup were augmented with structural allograft or trabecular metal (Fig. 1). Structural allograft was used from 2001 until 2006, and trabecular metal augments were used in selected cases after April 2004.

If the segmental defect was augmented with structural allograft, a fresh-frozen distal femoral allograft was thawed in warm saline and the articular cartilage removed. The femoral condyle was contoured to fit the segmental acetabular defects using the remaining superior ilium as a buttress to prevent proximal migration (Fig. 2A). The allograft was then impacted into place using a bone tamp and secured to the pelvis with screws. The inferior portion of the allograft was reamed to provide a hemispheric shape to the acetabular cavity. A reconstructive cage (Contour; Smith and Nephew, Memphis, TN) was then shaped to fit the acetabular cavity 
Fig. 2A-D (A) A distal femoral allograft has been placed into a superior segmental acetabular defect. (B) The allograft and host acetabulum were reamed and a reconstructive cage (Contour; Smith and Nephew, Memphis, $\mathrm{TN})$ the same diameter as the final reamer was used. (C) Palacos cement (Zimmer, Warsaw, IN) was mixed and placed over the back surface of the cage before implantation. (D) Screws were placed through the cage and into the host bone, and a UHMWPE liner was then commented into the cage.
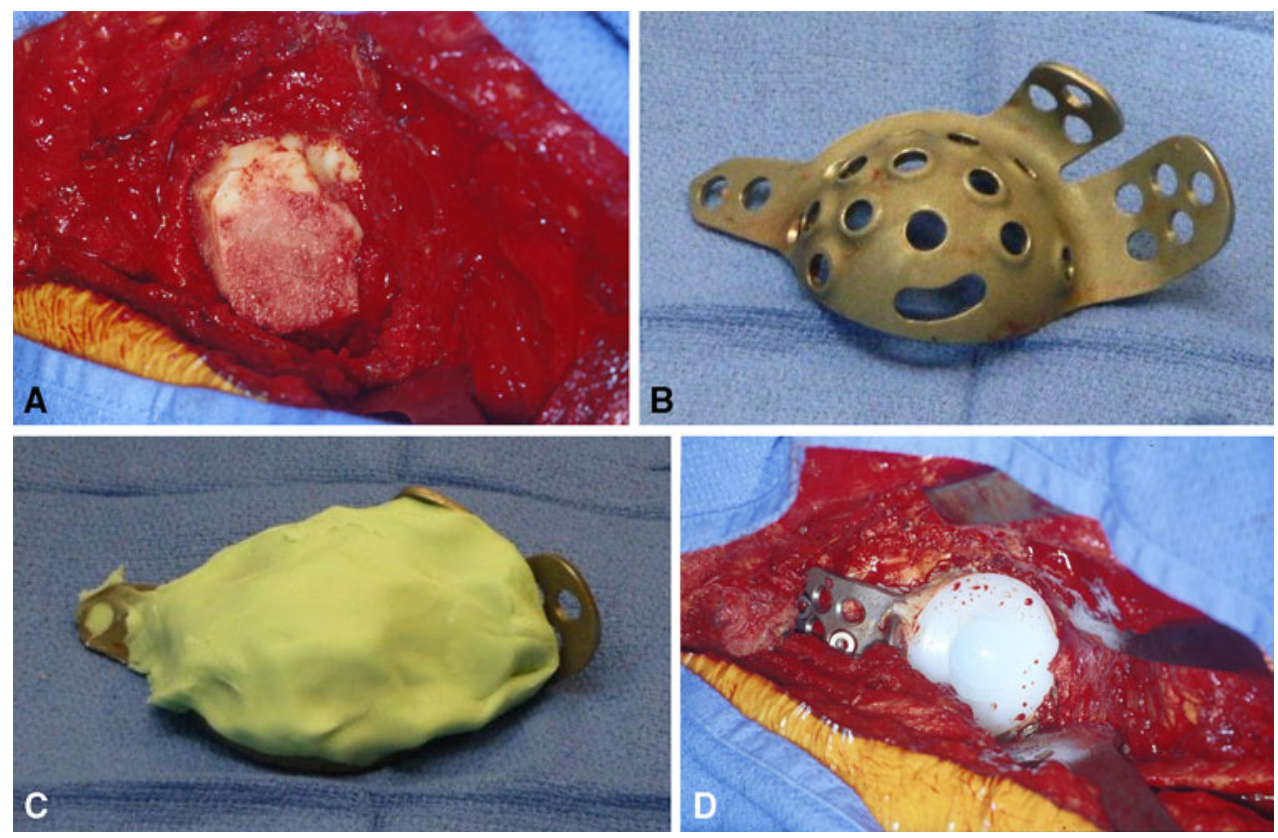

and pelvis (Fig. 2B). Discontinuity was evaluated by applying pressure to the superior acetabulum or ilium to observe any motion between the superior acetabulum and ischium. If discontinuity was present, a relatively large (greater than $60 \mathrm{~mm}$ diameter) cage was selected to effectively stabilize the discontinuity by distraction. The inferior flange of the cage was placed in a trough, which had been created in the ischium using a high-speed burr or curette. The cage was then removed and morselized allograft packed into cavitary defects. The morselized allograft consisted of freshfrozen corticocancellous chips of the same size and mechanical characteristics as typically used in impaction grafting procedures. One pack of Palacos cement (Zimmer) was mixed and placed along the back surface of the cage in a doughy state (Fig. 2C). The cage was then impacted into place and excess cement removed. While the cement was still in a doughy state, one screw was placed through the dome of the cage into the pelvis and two to three additional screws were placed through the proximal flanges into the pelvis. A second pack of cement was then mixed and an acetabular liner cemented into the cage (Fig. 2D). The liner was cemented in approximately $40^{\circ}$ of abduction and $20^{\circ}$ of anteversion independent of the cage position.

If the segmental defect was augmented with trabecular metal instead of structural allograft, a trabecular metal augment (Zimmer) was selected to fit the superior and posterior segmental defect. The augments are available in crescent shapes of various sizes to fit against the remaining interior host bone of the ilium or "number 7" shapes, which are placed along the outer cortical surface of the ilium deep to the abductor muscles. The defect was prepared with a reamer or burr to provide a contour similar to the augment, which could then be impacted into place and fixed with screws. A reconstructive cage (Contour; Smith and Nephew) was shaped and the inferior flange placed in a trough in the ischium. The cage was then removed and morselized allograft packed into any cavitary defects. Palacos cement (Zimmer) was mixed and placed along the back surface of the cage. It was then impacted into place and excess cement removed. The augment limited use of screw fixation through the cage. In a typical case, one screw was placed through the proximal flange of the cage into the pelvis while the cement was in a doughy state. A second pack of cement was then mixed and an acetabular liner cemented into the cage (Fig. 3). Estimated blood loss for the cases was $1114 \mathrm{cc}(\mathrm{SD} \pm 772 \mathrm{cc})$, and the average length of the case was 173 minutes ( $\mathrm{SD} \pm 42$ minutes).

Postoperatively, patients were mobilized on postoperative Day 1 with posterior hip dislocation precautions and toe-touch weightbearing using a four-wheel walker. Physiotherapy was initiated on postoperative Day 1 as is customary for the patients undergoing arthroplasty at our institution and consisted of a single 30 minutes to hour daily session focusing on compliance with hip precautions, safety with out-of-bed mobilization, and gait training. Toetouch weightbearing was continued for 6 weeks after surgery and then advanced to $50 \%$ weightbearing. Full weightbearing was permitted 12 weeks after surgery.

Patients were asked to followup in our outpatient clinic at 6 weeks, 3 months, 6 months, and each year after surgery. We obtained an AP radiograph of the pelvis and lateral radiograph of the involved hip preoperatively and at each followup visit. We obtained clinical data on all patients through review of the arthroplasty database and operative records. 
Two of us (EH, MDR) independently evaluated all radiographs. In cases of disagreement, radiographs were reviewed by both authors together until consensus was reached. Magnification of all radiographs was corrected for by use of the known diameter of the femoral head. We obtained calibrations and measurements using commercially available diagnostic imaging software (Image $\mathbf{J}($ ) National Institutes of Health, Bethesda, MD). Immediate postoperative radiographs were compared with radiographs obtained at the most recent followup for the following: (1) acetabular cage migration; (2) radiolucencies at the cagecement and cement-bone interface; and (3) hardware failure. Migration of the acetabular cage was measured relative to Kohler's line and the interteardrop line on serial radiographs $[10,16]$. We recorded measurements for both linear (mediolateral, superoinferior) and rotational (comparing cage abduction angles) migration. The cage abduction angle was measured between the lateral opening of the cage and the horizontal interteardrop reference line. Acetabular radiolucencies were scored according to DeLee and Charnley and were considered present if the radiolucent line measured at least $2 \mathrm{~mm}$ in width [7]. Radiographic failure was defined as a progressive circumferential radiolucency greater than $2 \mathrm{~mm}$ in three zones, a $10^{\circ}$ change in abduction angle, greater than or
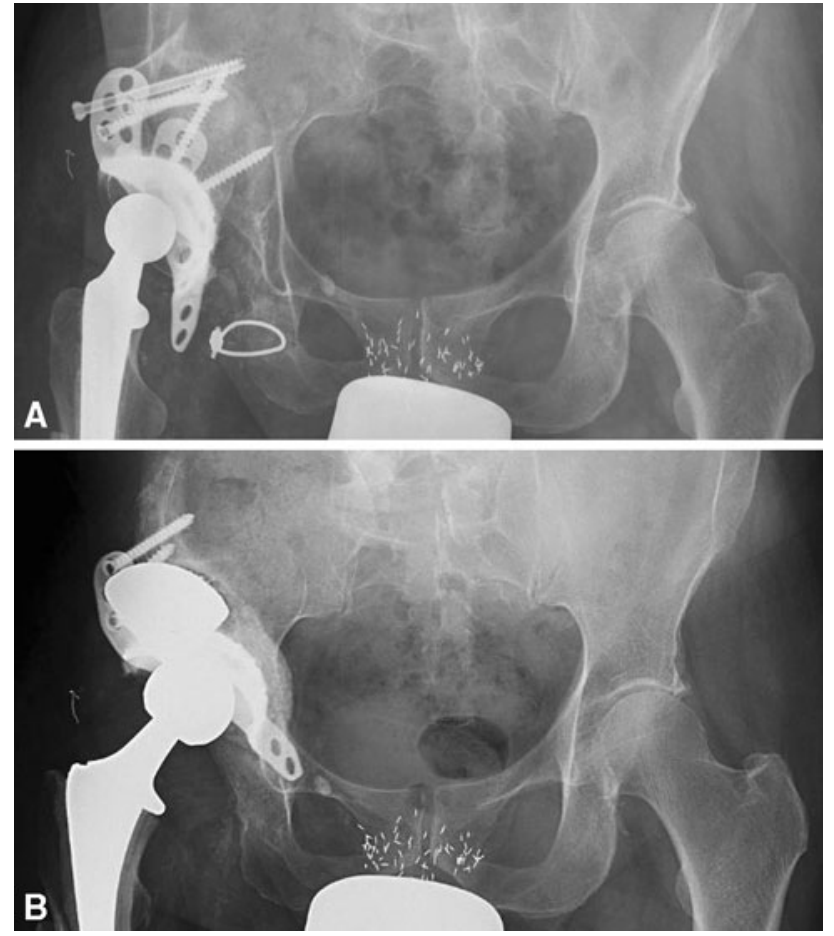

Fig. 3A-B (A) An AP radiograph demonstrates failure of a cemented cage reconstruction as a result of nonunion of a superior structural allograft for a Type 3B defect. (B) Stable fixation of a revision THA was achieved by converting the allograft to a trabecular metal augment with cemented cage. equal to $6 \mathrm{~mm}$ of combined linear displacement, or a broken cement mantle and screws [31,38]. There is substantial variability in assessing acetabular loosening using these methods, with reported kappa for interobserver reliability ranging from 0.49 to 0.63 [19].

Our primary outcome was mechanical failure, defined as revision of the acetabular reconstruction as a result of aseptic loosening. Failure resulting from infection and radiographic evidence of failure not resulting in revision surgery were considered secondary outcomes. We used Kaplan-Meier survivorship analysis to compare the failure rate for patients with and without pelvic discontinuity, and the log-rank test was used for hypothesis testing $[8,9]$. Kaplan-Meier curves were also constructed to analyze mode of failure for each treatment group. We report the 5year rate of mechanical failure derived from the KaplanMeier methods because it is most appropriate for time-toevent data with variable followup time; however, for the purposes of comparison with historical controls, the cumulative failure rate, defined as the percentage of mechanical failures among the total number of patients, is reported in the Discussion. There were no missing data.

\section{Results}

The cemented cage technique resulted in favorable mechanical stability for Type $3 \mathrm{~A}$ and $3 \mathrm{~B}$ defects without discontinuity (Table 2). The rate of mechanical failure was

Table 2. Mechanical failure rates for Paprosky Type 3 defects comparing the current study to historical controls

\begin{tabular}{llllc}
\hline Lead author & $\begin{array}{l}\text { Number } \\
\text { of patients }\end{array}$ & Followup & $\begin{array}{l}\text { Pelvic } \\
\text { discontinuity }\end{array}$ & $\begin{array}{c}\text { Cumulative } \\
\text { mechanical } \\
\text { failure }\end{array}$ \\
\hline $\begin{array}{l}\text { Hansen et al. } \\
\text { [current study] }\end{array}$ & 22 & 6 years & No & $9 \%$ \\
$\begin{array}{c}\text { Bostrum et al. } \\
\text { [4] }\end{array}$ & 31 & 10 years & No & $7 \%$ \\
$\begin{array}{c}\text { Goodman et al. } \\
\text { [13] }\end{array}$ & 48 & 5 years & No & $24 \%$ \\
$\begin{array}{c}\text { Berry and } \\
\text { Muller[3] }\end{array}$ & 42 & 5 years & No & $12 \%$ \\
$\begin{array}{l}\text { Regis et al. [29] } \\
\text { Gross [14] }\end{array}$ & 56 & 12 years & No & $9 \%$ \\
$\begin{array}{l}\text { Udomkiat } \\
\text { et al. [36] }\end{array}$ & 64 & 7 years & No & $14 \%$ \\
$\begin{array}{l}\text { Hansen et al. } \\
\text { [current study] }\end{array}$ & 13 & 6 years & No & $9 \%$ \\
$\begin{array}{l}\text { Goodman } \\
\text { et al. [13] }\end{array}$ & 48 & 5 years & Yes & $50 \%$ \\
$\begin{array}{l}\text { Paprosky } \\
\text { et al. [25] }\end{array}$ & 16 & 5 years & Yes & $31 \%$ \\
\hline
\end{tabular}



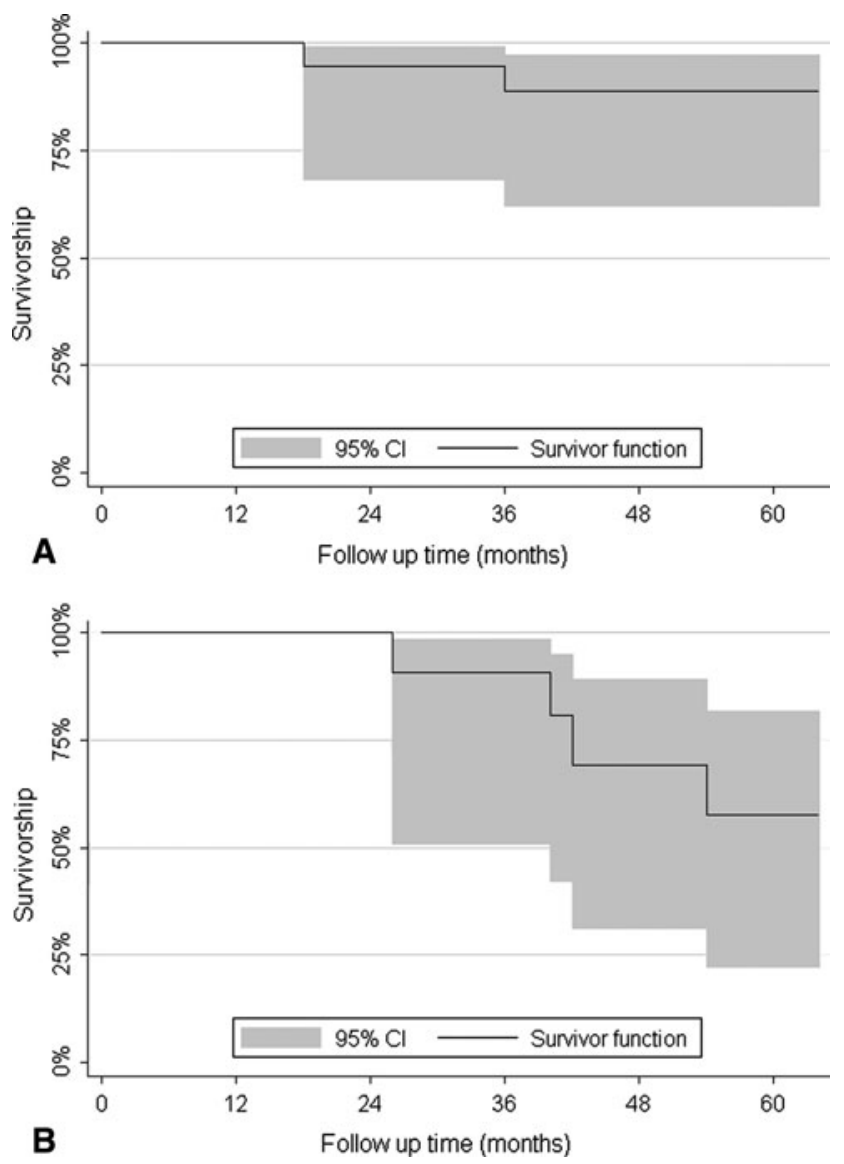

Fig. 4 Kaplan-Meier survival curves for mechanical failure for patients with $3 \mathrm{~A} / 3 \mathrm{~B}$ defects $(\mathbf{A})$ and pelvic discontinuity (B).

highest $(\mathrm{p}=0.13)$ among patients with pelvic discontinuity with an estimated 5-year survival rate of $57.7 \%(95 \%$ CI, $22.1 \%-81.9 \%$ ) compared with $88.8 \%$ (95\% CI, 62.1\%97.1\%) for patients without discontinuity (Fig. 4). There were no mechanical failures reported among patients treated with trabecular metal in the limited period of followup available. For patients without pelvic discontinuity, the 5-year rate of failure was $25 \%$ (95\% CI, $11.0 \%-50.9 \%)$ resulting from infection and $12.5 \%$ (95\% CI, 1.9\%-69.3\%) resulting from radiographic lucency. For patients with pelvic discontinuity, the 5-year rate of failure was $14.3 \%$ (95\% CI, 3.8\%-46\%) resulting from infection and the only failure resulting from radiographic lucency occurred at 52 months. All patients with radiographic evidence of loosening were asymptomatic.

Of the six patients who had a mechanical failure necessitating further revision surgery, three had incorporated enough structural bone allograft to allow placement of a hemispheric cup. There were no secondary mechanical failures of this cohort of patients at short-term followup.

The most frequent complication was prosthetic joint infection involving the reconstruction cage, which occurred in six patients (seven hips). Among these patients, risk factors for infection included splenectomy $(\mathrm{n}=2)$, endstage renal disease $(\mathrm{n}=1)$, malignancy $(\mathrm{n}=1)$, rheumatoid arthritis on steroids $(\mathrm{n}=1)$, chronic viral hepatitis $(\mathrm{n}=1)$, smoking $(\mathrm{n}=3)$, obesity $(\mathrm{n}=1)$, and a history of staged treatment for prosthetic joint infection $(n=1)$. Three patients were treated successfully with two-stage exchange arthroplasty, two were converted to a total femoral bipolar prosthesis after antibiotic spacer, and one required hip disarticulation for persistent infection. Postoperative dislocation occurred in five patients (five hips [11\%]) after cemented cage reconstruction. Four of the patients received 28-mm femoral heads, whereas one received a $32-\mathrm{mm}$ head. Instability was the primary indication for the revision arthroplasty in two of these patients. These dislocations were managed with closed reduction in two patients (mean, 5 weeks postoperatively), whereas the other three patients underwent revision acetabular surgery (mean, 33 weeks postoperatively) and had no further episodes of instability. Additionally, there were three perioperative deaths that occurred after acetabular reconstruction.

\section{Discussion}

Revision arthroplasty in the setting of severe acetabular bone loss or pelvic discontinuity is one of the most challenging clinical situations for the adult reconstruction surgeon. Although initial research performed by Gill et al. using acetabular cages with segmental allografts reported greater than $95 \%$ radiographic evidence of full incorporation and greater than $90 \%$ good or excellent subjective clinical outcomes, multiple other studies have demonstrated high rates of mechanical failure, which may be related to the inability for long-term biologic fixation at the implant-graft interface $[12,13,36]$. We believe that because the cage is typically attached to the pelvis and bone graft with screws, and then a liner is cemented into the cage, very little cement likely penetrates through the screw holes of the cage. However, the surface of the cage is not porous-coated or designed for cementless fixation. The lack of a cement bond at the interface between the bone and cage may contribute to mechanical failure of the reconstruction. Our technique of extensively cementing the cage to the allograft or trabecular metal and pelvis was intended to provide a mechanically stable interface between the cage and pelvic bone. We therefore (1) described this technique of cage cementation for patients with severe acetabular defects; (2) compared the survivorship of the technique to historical controls using mechanical failure as a primary end point in patients with Type 3 defects with and without pelvic discontinuity; and (3) analyzed patients who required further revision to determine the 
ability of this technique to restore adequate bone stock and facilitate conversion to a cementless hemispheric cup.

Our study is associated with several notable limitations. First, the absence of a control group makes it difficult to draw conclusions regarding the impact of the novel cementation technique relative to other surgeon and patient-related factors that may affect outcome. Although there are published data that serve as a historical control, it is not possible to adjust for confounding between studies. Second, data were collected retrospectively by the authors from electronic medical records, which may be incorrect, incomplete, or subject to biased interpretation. We aimed to minimize the impact of such bias by using a firm primary end point: revision arthroplasty. However, using this outcome does introduce the element of surgeon choice, which may not be consistent across studies. Third, although this is among the larger series of patients with these severe acetabular defects, the confidence intervals remain wide as a result of the small sample size. Lastly, the minimum followup of 2 years does not allow accurate assessment of the long-term efficacy of the technique, particularly in the small subgroup of patients treated with trabecular metal that had a shorter followup.

For Type 3 acetabular defects, it appears our technique of cementing the cage to the allograft or trabecular metal and pelvis has resulted in a lower rate of mechanical failure compared with historical controls. Multiple authors [14, 27, 36] have cited high rates of long term failure using structural allografts and reconstruction cages for Type 3 acetabular defects, which may be the result of the inability for biologic fixation and ultimate fatigue failure of the screws or flanges of the cages over time. At an average followup of 7 years, Gross et al. demonstrated $76 \%$ survivorship of reconstruction cages when structural graft supported greater than $50 \%$ of the implant [14]. Similarly, in another series of 62 patients (64 hips), the overall 6.7year survivorship using revision of the acetabular reinforcement device as the end point was $77.4 \%$ [36]. Although Regis et al. in the series with the longest followup to date reported only a 9\% (five of 56) rate of aseptic loosening at 11.7 years followup [29], unacceptable rates of failure as high as $64 \%$ have been reported using this technique for Type IIIB defects by Paprosky himself [27].

The inherent lack of bony stability in the setting of pelvic discontinuity results in an even higher incidence of early component loosening and clinical failure than the Type 3 defects. Goodman et al. analyzed 10 cases of pelvic discontinuity treated with ilioischial cage and structural allograft, in which eight patients had complications and only $50 \%$ had successful outcome, defined as no additional acetabular revision surgery and a stable reconstruction with incorporation of bone graft without fracture or resorption [13]. Similarly, Bostrum et al. noted a $50 \%$ rate of mechanical loosening at 2- to 5-year followup when they did a subanalysis of their cases with pelvic discontinuity [4]. Of our 13 patients with pelvic discontinuity, $31 \%$ (four of 13 ) had mechanical failure for which they had further revision, which occurred at a mean of 5 years after the initial surgery. Although it is difficult to make comparisons between series because of the small numbers, the modest improvement in survivorship with mechanical failure as an end point seen with our cemented cage technique may be attributable to the additional stiffness/rigidity imparted to our construct. However, our failure rate for pelvic discontinuity remained high, leading us to the use of trabecular metal augmentation in an effort to achieve more durable reconstruction.

Because progressive bone loss is encountered at each subsequent revision arthroplasty, restoration of bone stock is one of the important goals of revision arthroplasty. In our series, more than half of those patients considered clinical failures (60\% [three of five]) had in fact incorporated their prior structural bone graft by the time of the second revision operation. This allowed for revision surgery using a large hemispheric porous-coated cup. Goodman et al. noted that in a number of their "failed" cases, the bone graft and reconstruction ring were left in situ and thus may be considered "somewhat successful" [13]. Similarly, Gross et al. reported six hips in six patients that required revision for cup loosening all had intact and united allografts [15]. Therefore, in these complex cases, it is reasonable to consider the revision surgery as the first of two steps with restoration of bone stock as more important than the length of implant survival [28].

The unique structural and biomechanical properties of porous tantalum has attracted clinical and research interest for addressing severe acetabular bone loss and pelvic discontinuity. In 10 patients at a mean followup of 3 years using this technique no patient had mechanical failure, which is similar to that reported elsewhere in the literature. Using porous tantalum acetabular components for Type 3A defects, Sporer and Paprosky reported 100\% survivorship as defined by revision surgery for mechanical loosening of 28 hips at 3.1 years followup [34]. At a similar followup (2.8 years), Weeden et al. reported an overall success rate of $98 \%$ for Type 3A/B defects and no failures resulting from mechanical loosening [37]. In a series published out of the Mayo Clinic, including 16 patients at 32-month mean followup, there was no evidence of migration or loosening of their modular acetabular constructs [24]. In the setting of pelvic discontinuity, a series by Sporer and Paprosky demonstrated 12 of 13 hips were radiographically stable with only one being possibly loose at a mean followup of 2.6 years [33]. The most recent publication on the use of a trabecular metal cage construct with the largest series (26 hips) and longest followup (46 months) reported a $12 \%$ mechanical failure rate [18]. 
In summary, our analysis of a novel cemented cage reconstruction technique for Type 3 acetabular defects demonstrated a moderately lower rate of revision resulting from mechanical failure than prior studies. Among patients with pelvic discontinuity, the survival rate for mechanical failure of the cemented cage reconstruction was slightly more favorable than other published series using segmental allograft and cage constructs, but we consider our failure rate of $31 \%$ unacceptably high. In these cases, trabecular metal augments used in conjunction with hemispheric cups and cages may hold greater promise for improved implant survivorship. However, because porous tantalum constructs do not restore bone stock, for younger patients in whom further revision surgeries are expected, a technique of cementing the cage to structural allograft may be a more appropriate option.

Open Access This article is distributed under the terms of the Creative Commons Attribution Noncommercial License which permits any noncommercial use, distribution, and reproduction in any medium, provided the original author(s) and source are credited.

\section{References}

1. Berry DJ. Antiprotrusio cages for acetabular revision. Clin Orthop Relat Res. 2004;420:106-112.

2. Berry DJ, Harmsen WS, Cabanela ME, Morrey BF. Twenty-fiveyear survivorship of two thousand consecutive primary Charnley total hip replacements: factors affecting survivorship of acetabular and femoral components. J Bone Joint Surg Am. 2002;84: 171-177.

3. Berry DJ, Muller ME. Revision arthroplasty using an anti-protrusio cage for massive acetabular bone deficiency. J Bone Joint Surg Br. 1992;74:711-715.

4. Bostrom MP, Lehman AP, Buly RL, Lyman S, Nestor BJ. Acetabular revision with the Contour antiprotrusio cage: 2- to 5-year followup. Clin Orthop Relat Res. 2006;453:188-194.

5. Bozic KJ, Kurtz SM, Lau E, Ong K, Vail TP, Berry DJ. The epidemiology of revision total hip arthroplasty in the United States. J Bone Joint Surg Am. 2009;91:128-133.

6. D'Antonio JA, Capello WN, Borden LS, Bargar WL, Bierbaum BF, Boettcher WG, Steinberg ME, Stulberg SD, Wedge JH. Classification and management of acetabular abnormalities in total hip arthroplasty. Clin Orthop Relat Res. 1989;243:126137.

7. DeLee JG, Charnley J. Radiological demarcation of cemented sockets in total hip replacement. Clin Orthop Relat Res. 1976; 121:20-32.

8. Dobbs HS. Survivorship of total hip replacements. J Bone Joint Surg Br. 1980;62:168-173.

9. Dorey F, Amstutz HC. The validity of survivorship analysis in total joint arthroplasty. J Bone Joint Surg Am. 1989;71:544-548.

10. Dorr LD, Wan Z. Ten years of experience with porous acetabular components for revision surgery. Clin Orthop Relat Res. 1995;319:191-200.

11. Garbuz D, Morsi E, Gross AE. Revision of the acetabular component of a total hip arthroplasty with a massive structural allograft. Study with a minimum five-year follow-up. $J$ Bone Joint Surg Am. 1996;78:693-697.
12. Gill TJ, Sledge JB, Muller ME. The management of severe acetabular bone loss using structural allograft and acetabular reinforcement devices. J Arthroplasty. 2000;15:1-7.

13. Goodman S, Saastamoinen H, Shasha N, Gross A. Complications of ilioischial reconstruction rings in revision total hip arthroplasty. J Arthroplasty. 2004;19:436-446.

14. Gross AE. Revision arthroplasty of the acetabulum with restoration of bone stock. Clin Orthop Relat Res. 1999;369:198-207.

15. Gross AE, Goodman S. The current role of structural grafts and cages in revision arthroplasty of the hip. Clin Orthop Relat Res. 2004;429:193-200.

16. Hansen E, Ries MD. Revision total hip arthroplasty for large medial (protrusio) defects with a rim-fit cementless acetabular component. J Arthroplasty. 2006;21:72-79.

17. Jasty M, Harris WH. Salvage total hip reconstruction in patients with major acetabular bone deficiency using structural femoral head allografts. J Bone Joint Surg Br. 1990;72:63-67.

18. Kosashvili Y, Backstein D, Safir O, Lakstein D, Gross AE. Acetabular revision using an anti-protrusion (ilio-ischial) cage and trabecular metal acetabular component for severe acetabular bone loss associated with pelvic discontinuity. J Bone Joint Surg Br. 2009;91:870-876.

19. Kramhoft M, Gehrchen PM, Bodtker S, Wagner A, Jensen F. Inter- and intraobserver study of radiographic assessment of cemented total hip arthroplasties. J Arthroplasty. 1996;11: 272-276.

20. Kurtz S, Mowat F, Ong K, Chan N, Lau E, Halpern M. Prevalence of primary and revision total hip and knee arthroplasty in the United States from 1990 through 2002. J Bone Joint Surg Am. 2005;87:1487-1497.

21. Kurtz S, Ong K, Lau E, Mowat F, Halpern M. Projections of primary and revision hip and knee arthroplasty in the United States from 2005 to 2030. J Bone Joint Surg Am. 2007;89: 780-785.

22. Leopold SS, Rosenberg AG, Bhatt RD, Sheinkop MB, Quigley LR, Galante JO. Cementless acetabular revision. Evaluation at an average of 10.5 years. Clin Orthop Relat Res. 1999;369:179-186.

23. Malchau H, Herberts P, Eisler T, Garellick G, Soderman P. The Swedish Total Hip Replacement Register. J Bone Joint Surg Am. 2002;84(Suppl 2):2-20.

24. Nehme A, Lewallen DG, Hanssen AD. Modular porous metal augments for treatment of severe acetabular bone loss during revision hip arthroplasty. Clin Orthop Relat Res. 2004;429: 201-208.

25. Paprosky W, Sporer S, O'Rourke MR. The treatment of pelvic discontinuity with acetabular cages. Clin Orthop Relat Res. 2006; 453:183-187.

26. Paprosky WG, Perona PG, Lawrence JM. Acetabular defect classification and surgical reconstruction in revision arthroplasty. A 6-year follow-up evaluation. J Arthroplasty. 1994;9:33-44.

27. Paprosky WG, Sporer SS, Murphy BP. Addressing severe bone deficiency: what a cage will not do. J Arthroplasty. 2007;22: 111-115.

28. Pollock FH, Whiteside LA. The fate of massive allografts in total hip acetabular revision surgery. J Arthroplasty. 1992;7:271-276.

29. Regis D, Magnan B, Sandri A, Bartolozzi P. Long-term results of anti-protrusion cage and massive allografts for the management of periprosthetic acetabular bone loss. J Arthroplasty. 2008;23: $826-832$.

30. Sembrano JN, Cheng EY. Acetabular cage survival and analysis of factors related to failure. Clin Orthop Relat Res. 2008;466: $1657-1665$.

31. Sporer SM, O'Rourke M, Chong P, Paprosky WG. The use of structural distal femoral allografts for acetabular reconstruction. Average ten-year follow-up. J Bone Joint Surg Am. 2005;87: $760-765$. 
32. Sporer SM, O'Rourke M, Chong P, Paprosky WG. The use of structural distal femoral allografts for acetabular reconstruction. Surgical technique. J Bone Joint Surg Am. 2006;88(Suppl 1):92-99.

33. Sporer SM, Paprosky WG. Acetabular revision using a trabecular metal acetabular component for severe acetabular bone loss associated with a pelvic discontinuity. J Arthroplasty. 2006;21: 87-90.

34. Sporer SM, Paprosky WG. The use of a trabecular metal acetabular component and trabecular metal augment for severe acetabular defects. J Arthroplasty. 2006;21:83-86.

35. Templeton JE, Callaghan JJ, Goetz DD, Sullivan PM, Johnston RC. Revision of a cemented acetabular component to a cementless acetabular component. A ten to fourteen-year followup study. J Bone Joint Surg Am. 2001;83:1706-1711.

36. Udomkiat P, Dorr LD, Won YY, Longjohn D, Wan Z. Technical factors for success with metal ring acetabular reconstruction. J Arthroplasty. 2001;16:961-969.

37. Weeden SH, Schmidt RH. The use of tantalum porous metal implants for Paprosky 3A and 3B defects. J Arthroplasty. 2007; 22:151-155.

38. Welten ML, Schreurs BW, Buma P, Verdonschot N, Slooff TJ. Acetabular reconstruction with impacted morcellized cancellous bone autograft and cemented primary total hip arthroplasty: a 10to 17-year follow-up study. J Arthroplasty. 2000;15:819-824. 